\title{
Performances híbridas no pensamento utópico de Modesto Brocos y Gomez (1852-1936)
}

\author{
Hybrid performances in the utopian thinking of \\ Modesto Brocos y Gomez (1852-1936)
}

\author{
Heloísa Selma Fernandes Cape1* \\ Geraldo Witeze Junior**
}

\begin{abstract}
Resumo: Este artigo tem como objetivo discutir as performances híbridas do pensamento de Modesto Brocos y Gomez. Utilizamos como fonte o livro Viaje a Marte (1930), obra ficcional que transita entre o gênero utópico e o modo anedótico. Para tanto, procuramos analisar a vinculação do autor ao gênero literário utópico e a sua relação com a sátira, ligando-os às discussões do final do século XIX e início do século XX sobre o embranquecimento do povo brasileiro, levando também em consideração as telas que pintou sobre o tema. Palavras-chave: Utopia. Sátira. Eugenia.
\end{abstract}

Abstract: This paper aims to discuss the hybrid performances in the thinking of Modesto Brocos y Gomez. It Uses as source the book Journey to Mars (1930), a fictional work that transits between the utopian genre and the anecdotal mode. For that it discusses the connection of the author to utopian literary genre and its relation to satire, linking them to the discussions of the late nineteenth and early twentieth centuries on the whitening of the Brazilian people, taking also into account his paintings on this subject.

Keywords: Utopia. Satire. Eugenics.

\footnotetext{
* Heloísa Selma Fernandes Capel. Professora do Programa de Pós-Graduação em História da UFG. Doutora em Educação pela Unesp. <hcapel@gmail.com>.

** Geraldo Witeze Junior. Professor dos Departamentos de História e Letras da UEG - Unid Jussara/GO. Ms em Teoria e História Literária pela Unicamp e Ddo em História pela UFG. $<$ woitze@gmail.com>.
} 
Este artigo tem como objetivo discutir as performances híbridas do pensamento de Modesto Brocos y Gomez. Utilizamos como fonte o livro Viaje a Marte (1930), obra ficcional que transita entre o gênero utópico e o modo anedótico. As performances híbridas no pensamento do autor, traços de uma identidade intervalar, podem ser percebidas na discussão sobre miscigenação e eugenia, fruto do seu tempo de produção, bem como nas análises da época, que, em tons satíricos, encenam a crítica à moralidade sexual e religiosa.

A reflexão parte do princípio que, se recorrermos à análise do conjunto de sua obra, há um pensamento na expressão artística de Modesto Brocos como pintor e escritor. Mas, afinal, em que se configuram as performances híbridas em pensamento? Nossa hipótese é que a performance de Modesto Brocos é algo que se expressa em um entre lugar: algo que se materializa no Brasil, mas se conforma como princípio na matriz cultural europeia. Deste dinâmico encontro, resulta uma performance poético-visual e textual que se localiza entre a utopia militante educativa e a desconfiança, entre o oportunismo conjuntural e a afirmação da hierarquia entre as culturas. Se Modesto Brocos é apresentado como ilustrador da solução do branqueamento miscigenador no Brasil, a ironia de sua representação fala-nos de sua tradição europeia e seus princípios eugênicos radicais. Por outro lado, a defesa da miscigenação é um princípio de sua literatura utópica, novela socialista, próxima do socialismo, em que o pintor escreve, sobre a igualdade entre os sexos e "união das raças". Nessa literatura, o pintor explora aspectos inverossímeis e, em tom anedótico sutil, promove a crítica social de sua época.

Modesto Brocos não pode ser pensado fora de seus diálogos. É um artista transcultural, por natureza. Em sua trajetória biográfica e artística, transitou entre continentes e estilos para conformar, materialmente, ideias, pensamentos, narrativas. Modesto Brocos nasceu em Santiago de Compostela e, depois de colaborar como gravador em Buenos Aires, transladou-se para o Rio de Janeiro em 1872. Até seu estabelecimento definitivo no Brasil, em 1890, Brocos esteve em Paris e Roma, local em que chegou a trabalhar por quatro anos. No Brasil, tornou-se, em 1875, aluno de Vitor Meireles e Zeferino da Costa na Academia Imperial de Belas Artes, instituição da qual seria professor em 1891. O pintor trabalhou como professor de desenho de figura e gravurista, atuação que vem sendo considerada uma das mais significativas no âmbito do ensino das artes plásticas e do desenvolvimento da técnica da gravura no Brasil. 
Modesto Brocos é conhecido no Brasil, em especial, por sua pintura de 1895, Redenção de Cã, comum em livros de história, notadamente quando tratam da discussão do processo de "embranquecimento", sob as preocupações da eugenia em voga no século XIX.

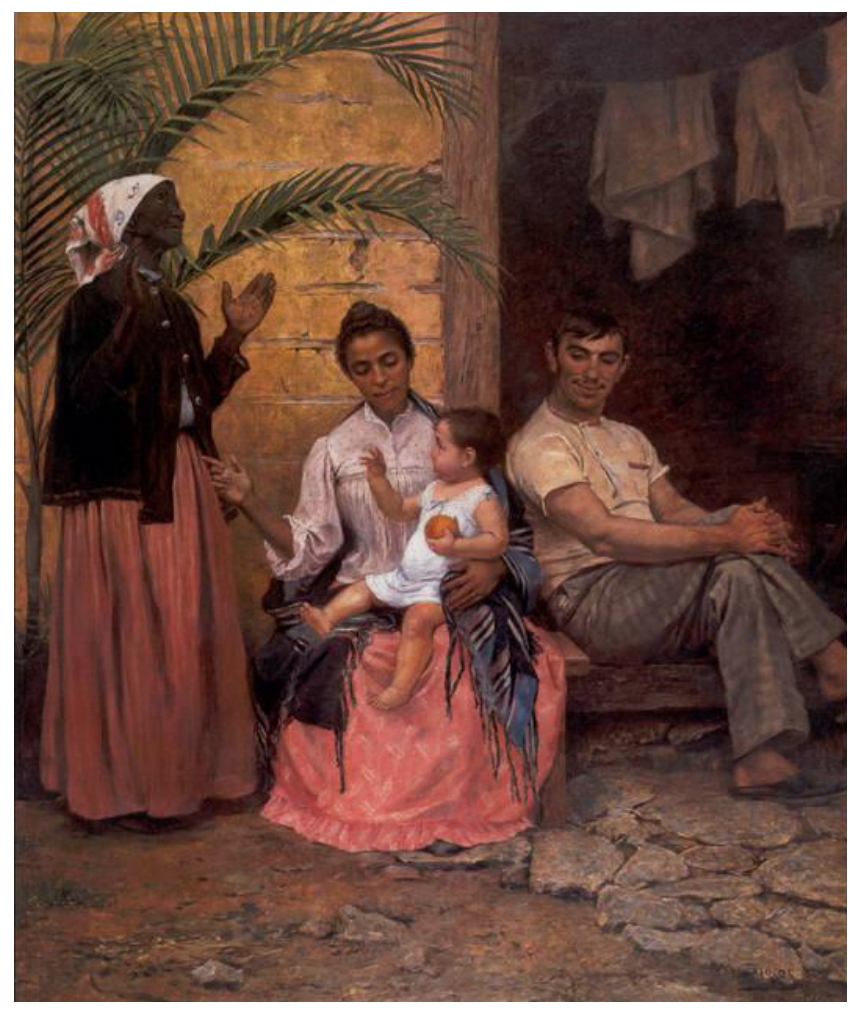

Redenção de Cã (óleo sobre tela, $199 \times 166 \mathrm{~cm}$ )

Modesto Brocos, 1895 - Rio de Janeiro Museu Nacional de Belas Artes.

Fonte: Ministério da Cultura/Assessoria de Imprensa.

Disponível em: <http://www.cultura.gov.br/site/2007/01/26/modesto-brocos-um-estrangeiro-nos-tropicos/>.

Na representação de Brocos, Cã, o personagem bíblico que deu origem aos negros e que teria sido amaldiçoado por seu pai Noé, obteria sua redenção no Brasil: em três gerações, o Brasil seria branco. No quadro de Modesto Brocos, a redenção da personagem bíblica se daria no seio da família com inspirações na iconologia cristã. A imagem de Brocos é uma evocação à Sagrada Família, com um novo nascimento: 
de uma criança branca, fruto da miscigenação de três gerações. Paiva interpreta que, para pintar o Brasil e seu futuro civilizado, Brocos, então, apresenta-nos uma Santana Negra, que levanta as mãos para o céu e agradece pelo nascimento da criança branca, personagem colocada no centro da tela, no colo de uma Virgem mulata e observada por seu pai, um São José entre o caboclo e o imigrante europeu (Paiva, 2004).

Sua interpretação alegórica e anedótica do assunto agradou o espectador do final do século na Academia. A Redenção de Cã é a obra com a qual o artista foi agraciado com a medalha de ouro no Salão de 1895. Sob o clima de discussão da identidade nacional, uma pintura de gênero que trouxesse elementos do processo de miscigenação no país era mais do que uma aspiração de correspondência direta com a realidade, era uma forma de ler o passado e contribuir com a expressão e a direção de expectativas para o futuro.

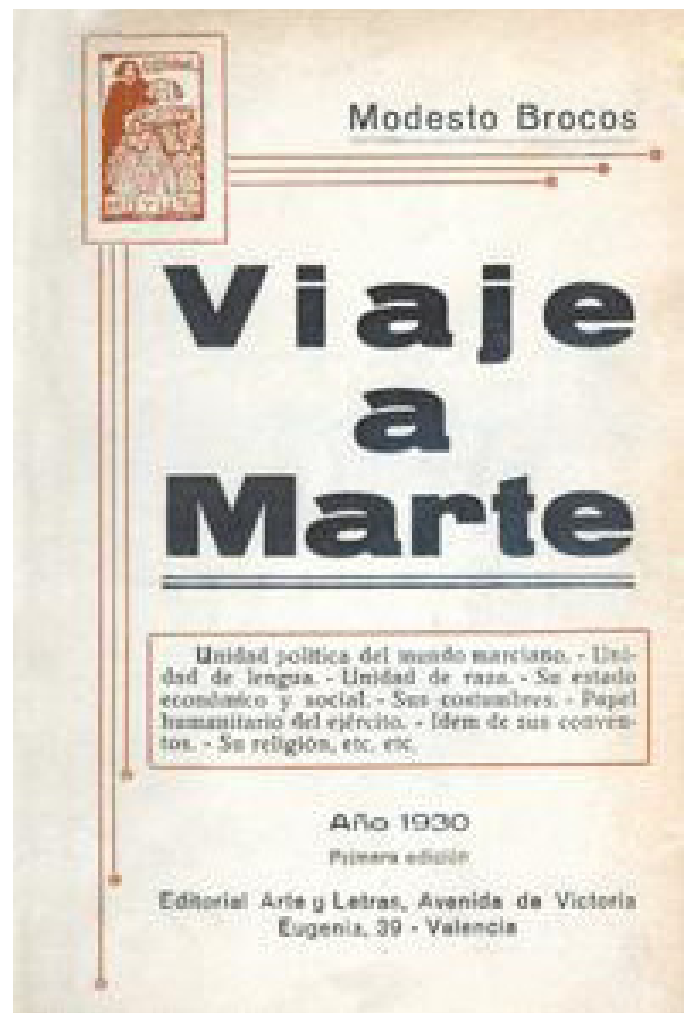

Viaje a Marte (capa)

Foto dos autores. 
Ao buscar compreender a obra do artista e seus diálogos, entretanto, é necessário um exame mais minucioso de sua rede de relações e do conjunto de sua obra, que, de forma ativa, desvelam um arcabouço próprio de pensamento e amplas possibilidades de interpretação. A opção retórica de Modesto Brocos está de acordo com suas utopias socialistas e foi expressa em texto no seu livro Viaje a Marte, publicado em 1930, na cidade de Valência. O livro foi pensado, segundo o autor, desde que tinha vinte anos e suas ideias amadurecidas em reflexões durante seu ofício como gravador, atividade que lhe conferia tempo para pensar. De inspiração claramente socialista, no Prólogo o autor começa por afirmar que uma ficção era necessária, pois o mal-estar de sua sociedade não se resolveria com regulamentos, "nem catecismos, nem com lei alguma, mas pela luta entre os que aspiram e os que resistem" (Brocos y Gomez, 1930, p. 11). O livro é escrito em primeira pessoa e contém referências históricas claras como o encontro com o personagem histórico Benito Jerónimo Feijoó y Montenegro (1676-1764), frade da Ordem de São Bento, intelectual ensaísta considerado representante da primeira Ilustração espanhola e considerado precursor da Enciclopédia. Feijoó é o guia do personagem-autor e o instrutor das mudanças processadas na sociedade marciana, que em uma época "bárbara", havia experimentado um tipo de vida como a que se vivia na Terra. A sociedade terrestre era o mundo de Modesto Brocos: o mundo configurado entre as sociedades espanhola e brasileira da segunda metade do século XIX e primeiros anos no século XX.

\section{Utopia como projeto realizável: a defesa da miscigenação}

Segundo Jaureguízar (2009), a opção do autor por Marte pode ter sido influenciada pelo fato de que, à época, o Planeta Vermelho era considerado o mais parecido com a Terra. Imagina, ainda, que o pintor-escritor pode ter conhecido a notoriedade do filme Aelita, utopia socialista em Marte rodada em 1924, por Yakov Protazanov ${ }^{1}$.

Em seu livro Viaje a Marte, Modesto Brocos y Gomez afirma o seguinte: "Es bien posible que tú lo leas como si fuera un romance, tus hijos también lo leerán como un pasatiempo, pero tus nietos tengo la certeza de que lo leerán con más atención que tú [...] Será muy

O filme se chama Aelita e foi baseado na novela homônima de Alexis Tolstoi. No filme, os soviéticos viajam para o país e lá fundam um Partido Socialista da República para derrubar a ditadura alienígena. 
posible que en el fin de tu vida veas realizadas algunas de las utopías que presento en este libro" (apud Jaureguízar, 2012). Aqui está posta a ideia da utopia como um projeto para a sociedade, algo bastante comum nas utopias.

Arrigo Colombo tratando da oposição entre a Utopia de Thomas More e a sociedade de seu tempo, afirma que:

A utopia, portanto, já na intenção de Morus, é aquela sociedade que não existe porque é a sociedade boa, justa, enquanto que as sociedades que existem são "iníquas", injustas. É para a sociedade justa que vai a tensão, o projeto humano, a sociedade de justiça em direção à qual a humanidade é impelida. (Colombo, 2006, p. 56-57).

Ora, se a humanidade é impelida para uma sociedade de justiça, onde estão os resultados? E uma pergunta ainda mais fundamental: quem ou o que impele os homens nessa direção? Sem tal resposta essa ideia se assemelha a uma crença, um pressentimento não confirmado que, se pode acontecer, vai contra todos os prognósticos e surpreende, porque não pôde ser percebido senão por alguns poucos. Dito de outra forma, é uma revelação para alguns iluminados, sem data para realização. A humanidade seria impelida para a justiça independentemente de sua vontade, como se fosse predestinada a isso, no melhor estilo calvinista. Com relação às utopias, é uma conclusão inverossímil, pois um dos ideais que sustentam é que o homem é o senhor do seu destino (Trousson, 2005); e o triunfo da vontade é o extremo oposto de qualquer noção de predestinação.

Entretanto, a Utopia "não é só um abstrato 'elogio da sabedoria', mas uma descrição analítica de ordenações justas criadas por homens sábios" (Quarta, 2006, p. 41). Aqui está uma característica fundamental do gênero que se formaria a seguir: as utopias são constituídas por ordenações justas que são invariavelmente o contrário ou a atenuação das injustiças da sociedade de seu autor. Raymond Trousson ajuda a esclarecer essa ideia:

Así, pues, sólo se pasa al género utópico, em el sentido estricto del término, si la reflexión sobre las posibilidades laterales acaba em la representación de un mundo específico, organizado. El pensador utópico, al crear uma utopía, vuelve acesibles sus hipótesis em forma de una ciudad en la que se organizan y se estructuran. (Trousson, 1995, p. 42). 
Sempre é importante ressaltar que o relato utópico não se reduz a uma forma única e constante. Em consonância com Jacques Gury, Trousson (2005, p. 132) afirma que "talvez não haja uma definição formal do relato utópico, mas antes uma série cronológica de definições respondendo ao porvir dos meios de expressão", ou seja, cada utopia deve ser definida com relação ao seu tempo. A partir do século XVIII, o elemento de afastamento passa a se diversificar, podendo ser um deslocamento temporal, uma história alternativa ou mesmo uma viagem para outros planetas. Nessa última forma está inserida a obra de Modesto Brocos y Gomez.

Em Viaje a Marte, podemos observar orientações sobre a justiça, a educação, além da igualdade de direitos entre os sexos, que deveria ser realizada a partir de uma raça única e de uma língua única. As preocupações com o cruzamento das raças já estariam presentes na sua obra, como resultado do clima da época: discussões europeias sobre as raças que oscilava entre uma reação à visão unitária da humanidade no Iluminismo - como pressuposto igualitário das revoluções burguesas - e concentração do debate em aspectos biológicos e culturais das doutrinas sociais.

Mas se Brocos y Gomez defendia princípios eugenistas, como podemos dizer que sua obra busca a justiça e a perfeição? Segundo L. T. Sargent (2005, p. 156), a utopia "does not describe a perfect society by any definition of perfect". Uma sociedade perfeita seria completa, e, portanto, imutável, estando assim afastada da História. Ora, foi no Renascimento, quando os humanistas de Florença perceberam a diferença entre esta e Atenas - considerada por eles a sua equivalente, seu espelho - que descobriram a especificidade da História, ou seja, que o homem é produto de circunstâncias históricas específicas e que é autor de sua existência individual (Heller, 1982). Assim nasce a concepção moderna de História, a percepção de que cada época é singular e que é sempre possível transformar a própria realidade. Portanto, nem a Utopia, gerada a partir dessa noção renascentista, nem as obras que seguiram seu rastro podem estar afastadas da História. Não podem também ser simplesmente vistas como conservadoras ou reacionárias, afinal, estão intimamente ligadas à ideia de transformação da sociedade, ou pelo menos dessa possibilidade. E nesse sentido, cada época e cada escritor vislumbrarão as suas possibilidades, e é natural que possa ocorrer que o mundo ideal de um período seja extremamente opressor para outro.

Além da sua vinculação com a história - no caso de Brocos y Gomez, com a discussão racial do fim do século XIX e começo do 
XX - é importante ressaltar que a utopia "é o sonho de um cidadão descontente com sua cidade, que não escolhe por paraíso de seus sonhos o que se opõe à cidade - paraísos artificiais ou campos árcades - mas outra cidade, organizada de outra maneira" (Dubois, 2009, p. 18). Por isso a discussão racial pode estar na utopia de Brocos y Gomez, já que, ao que tudo indica, ele considerava a questão importante para a construção de uma sociedade justa.

A concepção das raças naturalizava as diferenças e postulava o fim das leis naturais que previam um elo entre os homens de todos os povos. Lilia Moritz Schwarcz localiza esse debate na delimitação entre disciplinas afins como os estudos antropológicos ligados às ciências físicas e as análises etnológicas orientadas sob uma tradição humanista advinda de Rousseau: "Enquanto os estudos antropológicos nascem diretamente vinculados às ciências físicas e biológicas, em sua interpretação poligenista, as análises etnológicas mantêm-se ligadas a uma orientação humanista e de tradição monogenista" (Schwarcz, 1993, p. 53).

Entretanto, na concepção poligenista e com base nos estudos biológicos, a mistura de raças personificava a degeneração que poderia advir do cruzamento de espécies diversas ${ }^{2}$. Por outro lado, havia, também, uma espécie de darwinismo social que via com pessimismo a miscigenação, pois nem a evolução social poderia transmitir caracteres adquiridos. Se as raças eram fenômenos absolutos e o cruzamento um erro, havia a tendência de enaltecer a "pureza" das raças e condenar a miscigenação. A mestiçagem seria constitutiva de uma "degeneração" racial e social. Dessas discussões desenvolvem-se as concepções de eugenia como forte movimento científico e cultural que em 1880 se constitui em pensamento com pleno vigor. No início do século XX, o Brasil já conta com a fundação da Sociedade Eugênica em São Paulo (1918).

Os modelos de determinismo racial foram populares no Brasil, mas, segundo Schwarcz (1993), adquiriram uma feição própria combinando o darwinismo social com a perspectiva evolucionista e monogenista. Se esse modelo explicava as diferenças e as hierarquias entre as culturas,

2 "Com respeito a essa noção, conviviam, inclusive, argumentos variados. Enquanto Broca defendia a ideia de que o mestiço, à semelhança da mula, não era fértil, teóricos deterministas como Gobineau e Le Bon advogavam interpretações opostas, lastimando sempre a extrema fertilidade dessas populações que herdavam sempre as características mais negativas das raças em cruzamento. [...] As raças humanas deveriam ver na hibridização um fenômeno a ser evitado". (Schwarcz, 1993, p. 57). 
por outro lado, com algumas releituras, permitia pensar na possibilidade de uma nação mestiça. O pensamento sobre as raças no Brasil foi sistematizado, segundo a autora, em instituições de saber dos finais do século XIX que se configuraram no pensamento da elite nacional. Essas ideias se desenvolveram a partir dos museus etnográficos, dos institutos históricos brasileiros e das escolas de direito e medicina fundadas no Brasil no século XIX. Se o darwinismo social europeu acaba por adotar o suposto da diferença das raças, para se opor às ideias do século anterior ligadas ao iluminismo e ao pensamento rousseauniano, no Brasil, desenvolve especificidades favorecidas pelo projeto liberal, enfraquecimento da escravidão, rigidez hierárquica entre as categorias sociais, além da conjuntura de favorecimento da imigração estrangeira. O que significa dizer que no Brasil, em que pesem as opiniões contrárias aqui e ali, a tendência será de, ao final do século, admitir a miscigenação, não apenas como degenerescência, mas como formação e base de uma cultura que poderia se aperfeiçoar, elemento importante na conformação de uma nação republicana em pleno florescimento.

$\mathrm{O}$ darwinismo social europeu supõe as hierarquias naturais e o aperfeiçoamento constante das raças e, no Brasil, cientistas, políticos, pesquisadores e literatos, acadêmicos e missionários vão transitar entre a aceitação das teorias estrangeiras que condenavam o cruzamento racial e sua adaptação a um povo já miscigenado. Aqui, a interpretação darwinista social se combina com a evolucionista e a monogenista. Dos estudos de frenologia, leituras germânicas contra a miscigenação, análises liberais ou católico-evolucionistas, chegaremos à eugenia brasileira compreendida mais como problema de saúde e educação do que como um problema racial $^{3}$. Em 1929-1930, anos de publicação de Viagem a Marte, e do I Congresso Brasileiro de Eugenia (1929), já se defendia a imigração. A partir do século XX, o Brasil assumirá, de maneira predominante, a política do branqueamento como definidor de uma identidade nacional. É bastante interessante o que diz Augustín Jaureguízar sobre Brocos y Gomez:

Dijo asimismo que en su juventud había sido autoritario y soñaba con imponer sus ideas por la fuerza a quienes no las compartiesen, para en su madurez preguntarse si no sería preferible conservar la

"Marcado pelos ensinamentos genéticos de Mendel e pelo culturalismo norte-americano de Franz Boas, Roquete Pinto sustentou o argumento de que o 'problema brasileiro seria uma questão de higiene e não de raça'. Posicionou-se, também, a favor da introdução de imigrantes japoneses, contrariando a posição majoritária de cientistas médicos." (Schwarcz, 1993, p. 96). 
organización del mundo tal cual era, contentándose con corregir sus defectos y dignificar sus instituciones: tal es la decidida intención de su obra. (Jaureguízar, 2012).

A utopia, como sonho ou projeto de um indivíduo, atesta o triunfo da vontade e da individualidade humanas, pois é o homem que a cria, propõe e realiza. É um mundo humano, que "recusa a submissão à transcendência," não pela rejeição a Deus, mas por assumir seu papel criador, sua inserção na história e a singularidade de cada época. $\mathrm{O}$ homem é o sujeito da história, e não um títere no jogo divino. Aí está sua dignidade. Assim, "a utopia propõe a redenção do homem pelo homem" (Trousson, 2005, p. 130), pois este, semelhante a Deus, deve usar os atributos divinos que tem - a criatividade, o poder e o conhecimento para construir uma sociedade feliz. Afinal, Deus pôs o homem acima de todos os seres da criação ${ }^{4}$ e é natural esperar que o tenha dotado dessa capacidade realizadora. $\mathrm{O}$ homem não pode criar da mesma forma que Deus, a partir do nada, mas pode transformar. É o conflito entre "um sentimento trágico da história" e a "vontade de dirigir o seu curso" (Trousson, 2005, p. 130) que origina a proposta utópica.

Ela nasce "de fato, da aguda consciência, que é ao mesmo tempo crítica e ética, dos males sociais e da vontade de superá-los" (Quarta, 2006 , p. 51). O homem observa a humanidade e percebe a queda, de alguma forma a reconhece, e quer resistir a ela, quer seguir na direção contrária. "Com efeito, se a utopia - assim como o utopismo - supõe a vontade de construir, frente à realidade existente, um mundo outro e uma história alternativa, ela se revela essencialmente humanista ou antropocêntrica, na medida em que, pura criação humana, ela faz do homem mestre de seu destino" (Trousson, 2005, p. 128). Numa contradição, o destino do homem seria então controlar a sua história ou, melhor dizendo, ao dotar o homem da razão e dos sentidos, Deus teria conferido a ele essa singular capacidade de dirigir o próprio destino.

A justiça buscada pelo utopista seria constituída de elementos fundamentais percebidos historicamente em maior ou menor grau. A utopia, nesse sentido, é a cristalização literária da percepção tida por um determinado indivíduo em uma determinada época histórica do que é uma sociedade justa. Ao afirmar quais são os direitos fundamentais dos homens e quais valores devem ser mantidos, o utopista abre a porta

4 Ver Gênesis I, 28: "Deus os abençoou e lhes disse: 'Sede fecundos, multiplicai-vos, enchei a terra e submetei-a; dominai sobre os peixes do mar, as aves do céu e todos os animais que rastejam sobre a terra"'. 
para o diálogo ${ }^{5}$ sobre a justiça e permite que, através disso, a sociedade em que vive possa se aproximar de um patamar mínimo de direitos.

Por outro lado, se o utopista adotar uma posição intransigente, assumindo que a sua ideia de justiça é absoluta, e se fechar para a discussão, ele estará transformando o aspecto totalizante de sua obra em totalitarismo. Isso poderia acontecer por causa da intransigência do utopista, da negação do diálogo - o que não é característica dos escritos utópicos - ou da tentativa de se por em prática algum projeto utópico exatamente como é, desconsiderando especificações históricas e geográficas. Mas é preciso ressaltar que as utopias não são sempre totalitárias, apenas apresentam de forma concreta um modelo de sociedade justa que poderá, sem dúvida, ser aprimorado com o passar do tempo.

Tudo isso nos faz perguntar qual era a concepção de justiça de Modesto Brocos y Gomez, especialmente com relação à questão racial. De acordo com a tradição utópica, sua visão é, por um lado histórica, ou seja, é indissociável das discussões do seu tempo. No livro de Brocos, vamos encontrar ideias eugênicas radicais, como a esterilização de pessoas com males incuráveis, ou mesmo a separação por município, de crianças nascidas com algum tipo de defeito físico para afogamento em uma piscina. Adepto do determinismo geográfico, o autor ainda considera que as mulheres mais saudáveis e belas deveriam ser escolhidas para procriar, esterilizando-se as demais.

Nada mais adequado à conjuntura vivida pelo pintor. A política de branqueamento das raças e as práticas e os debates sobre eugenia estavam em franca exposição no Brasil da virada do século XIX até as primeiras décadas do século XX. O pintor abandonava a perspectiva europeia de condenação à mistura racial, pela defesa brasileira da miscigenação, aspecto que contribuiria para que formasse um pensamento original sobre o Brasil. A busca da singularidade brasileira é seu agenciamento como europeu, sua oportunidade de atuar socialmente, configurando-se como "brasileiro" naturalizado.

Para além disso, existe já nas utopias que inauguraram o gênero, a Utopia de More e a Cidade do Sol de Campanella, uma discussão a respeito do casamento, considerando que a reprodução humana deve

\footnotetext{
Não se deve esquecer que muitas utopias, começando pela de More, adotam a forma do diálogo em suas narrativas. Isso de forma alguma é gratuito, ao contrário, remete a possibilidade de construção do estado ótimo através do debate de ideias, da busca da sabedoria, do aprendizado em conjunto e da humildade para ouvir.
} 


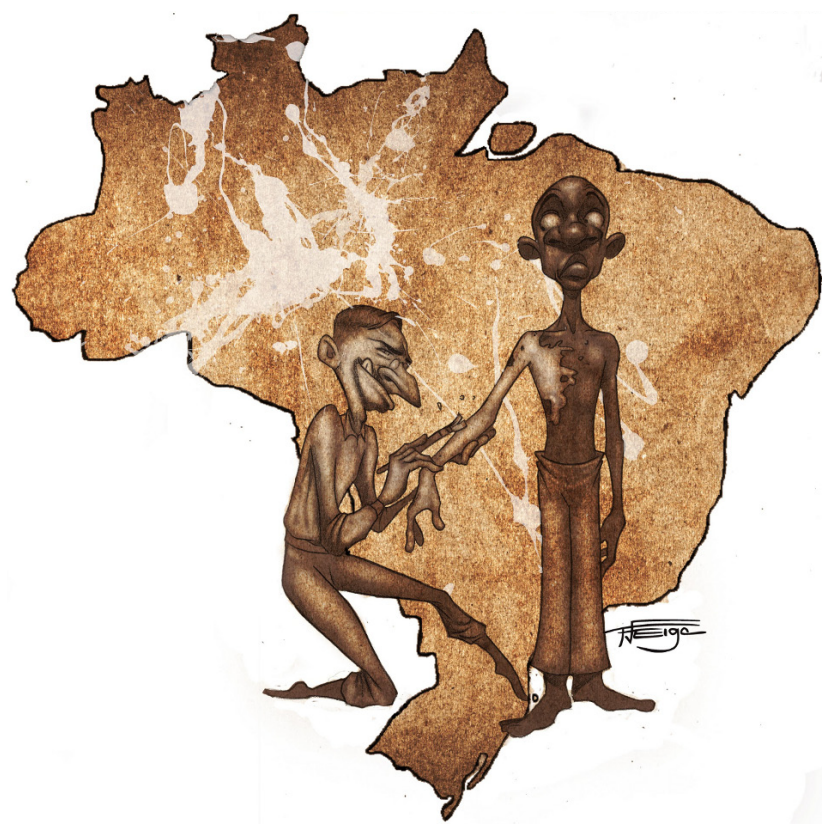

Embranquecimento do Brasil

Francisco Veiga, 2012 (imagem cedida pelo autor ${ }^{6}$ ).

atender ao princípio renascentista do equilíbrio. O sexo é altamente regulado, tendo em vista sempre o equilíbrio social. Na Utopia, as relações sexuais fora do casamento são severamente punidas, e na Cidade do Sol é praticada a comunidade das mulheres e o sexo é permitido aos homens fora do casamento apenas com mulheres estéreis, e isso somente para os que não conseguissem controlar seus impulsos. Vejamos o que diz Thomas More:

$\mathrm{Na}$ escolha de seus cônjuges, os utopienses observam com muito rigor e seriedade um costume que nos pareceu, no início, extremamente absurdo e tolo. A esposa, seja ela virgem ou viúva, é mostrada nua ao seu pretendente, sob os cuidados de uma mulher casada e respeitável e, do mesmo modo, um homem, de honorabilidade reconhecida, apresenta o noivo nu, à noiva. $[\ldots]$

Esta obra foi desenvolvida especialmente para esta publicação como uma releitura do pensamento de Modesto Brocos y Gomez. Mais informações sobre o autor, outras obras de sua autoria e seu contato estão disponíveis em: $<$ http://www.franciscoveigailustracao. blogspot.com/>. Acesso em: 03 set. 2012. 
Nem todas as pessoas são tão sábias que se preocupam somente com as belezas do caráter; e mesmo os sábios apreciam a beleza do corpo como um suplemento para um bom temperamento. Não há dúvida de que uma deformidade pode esconder-se sob as roupas e ser suficientemente séria para fazer com que um homem tenha aversão por sua mulher quando já é tarde demais para separar-se dela. (More, 2004, p. 94).

Aqui temos uma preocupação em evitar que determinados traços físicos levassem a uma decepção após o casamento, já que na ilha de Utopia o divórcio era permitido apenas em pouquíssimos casos, ainda assim depois de uma rigorosa investigação. Claro, é uma discussão com a cultura da Inglaterra de More, mas merece destaque o fato de o objetivo explícito do procedimento seja impedir o ocultamento de deformidades. Ou seja, há uma preocupação com o equilíbrio do corpo, com a simetria, com um padrão de beleza estabelecido, sendo que o desvio desse padrão poderia ser um motivo que impedisse o casamento.

Campanella vai um pouco além, dizendo o seguinte:

De acordo com o costume dos antigos espartanos, tanto os homens como as mulheres aparecem nus nos exercícios ginásticos, de forma que os preceptores têm a possibilidade de descobrir os que são capazes ou incapazes para a geração, podendo determinar ainda qual o homem mais conveniente a determinada mulher, segundo as respectivas proporções corporais. A união marital se realiza cada terceira noite e depois que os geradores estão bem lavados. Uma mulher grande e bela se une a um homem robusto e apaixonado, uma gorda a um magro, uma magra a um gordo, e assim, com sábio e vantajoso cruzamento, moderam-se todos os excessos.

$[\ldots]$

Sábia, por conseguinte, é a prescrição que lhes ordena a união com mulheres vivazes fortes e belas. Da mesma forma, os homens ágeis, ardentes, de temperamento sanguíneo, devem unir-se a mulheres gordas e frias. Dizem eles que, descurada a geração, não se pode depois, com a arte, adquirir a harmonia dos diversos elementos do organismo, causa de todas as virtudes, e que os homens nascidos com má organização só praticam o bem pelo receio da lei e de Deus. (Campanella, 2002, p. 23-24).

Seguindo a linha de More, a ideia aqui é obter boas proporções físicas. Os filhos resultantes dessa união seriam harmoniosos e não causariam desequilíbrios sociais, por serem bem gerados, de acordo 
com princípios científicos. Há uma clara relação entre a harmonia individual e social, daí a importância dada à geração. Daqui para a ideia de embranquecimento defendida por Brocos a partir de seu contexto histórico não há muita distância, especialmente se a justificativa for o equilíbrio entre as raças.

Não se trata de dizer que as utopias são racistas, pois isso seria um anacronismo grave, mas de compreender que cada obra está vinculada à realidade social, do seu tempo, mesmo seguindo uma determinada tradição literária. As utopias seguem certos padrões, mas são bastante diferentes entre si, havendo diversos debates para tornar possível a delimitação do gênero literário que constituem (Witeze Jr., 2010). Ao que tudo indica Brocos y Gomez segue a tradição renascentista de busca do equilíbrio, aplicando-a à questão racial em discussão no seu tempo, tentando pensar em como obter a harmonia social. Não fazemos aqui um mea culpa de Brocos Gómez, apenas tentamos compreender sua concepção de justiça, mesmo que ela seja insustentável em nosso momento histórico.

\section{Utopia como estranhamento: diálogos inverossímeis com modo anedótico}

Ideias paradoxais são mais aptas que as outras para afinar a acuidade do espírito.

THOMAS MORE

Embora Modesto Brocos y Gomez tenha enfatizado sua intenção de construir uma ficção que poderia se realizar no futuro, seu texto tem um traço irônico, o mesmo que encontramos em A Redenção de Cã. Esse elemento, embora não altere essencialmente o objetivo temático da obra, confere ao texto um sutil tom anedótico.

As anedotas, em seu modo satírico, são comuns nos textos utópicos. Segundo Ana Cláudia Romano Ribeiro, o modo satírico pode ser identificado em obras que não pertencem ao gênero da sátira, mas que a utilizam de algum modo. Como explica: "A modalidade satírica indica um ataque humorado nos campos da moral, da religião, da política e da literatura, que podemos encontrar expressos em vários gêneros" (Ribeiro, 2009, p. 140). As sátiras mais antigas, denominadas Menipeias ${ }^{7}$, por exemplo, possuíam hibridismo formal e a presença de

Sátiras que encontram sua formalização literária em Menipo de Gadara (séc. IV e III a.C.) e que podemos ler em Diógenes Laércio (200 - 250d.C). 
certa ambiguidade, o que faria com que aquele que a lesse ficasse em dúvida se era uma obra "séria"ou "cômica".

O hibridismo formal das utopias seria, então, uma questão comum, havendo, então, mistura de gêneros histórico, ficcional, retórico ou mesmo filosófico. No jogo de seu desejo de perfeição há muita inverossimilhança, um traço que acentua o fato que a utopia é, fundamentalmente, um discurso crítico de sua época. Segundo Ribeiro (2009), é justamente esse jogo entre verossimilhança versus inverossimilhança que torna o texto irônico e ambíguo. Para comprovar a ideia, Ribeiro explora a Utopia de Thomas More e comenta que a discussão sobre situações e valores que seriam inconcebíveis na sociedade do autor, como igualdade social, mínimo de hierarquia política e religiosa, dentre outros, seriam os elementos que levariam à discussão e ao estranhamento do leitor sobre seu mundo conhecido (p. 143). Embora não tenha construído um pensamento com gênero satírico, o tom anedótico na obra de Brocos seria, nessa perspectiva, uma forma de acentuar o estranhamento em relação ao seu mundo conhecido, favorecendo, assim, sua intenção crítica. Destaque-se que o pintor escritor possuía afinidades com o gênero, como comprovam suas xilogravuras publicadas no jornal satírico republicano $O$ Mequetrefe (1875). Estranhamentos são elementos fundamentais na compreensão. Como desenvolveu Gadamer (1997), no processo de interpretação, a compreensão é um acordo temporário que resulta do movimento interpelativo. Essa interpelação favorece processos identitários que se realizam pela diferença resultante dos constantes movimentos familiaridade/estranhamento, e esta dinâmica, em jogo, possibilita a compreensão. Na obra utópica de Brocos y Gomez, há utilização de recursos de estranhamento pelo inverossímil. Sua relação com a conjuntura histórica ocorre em perspectiva performática e contingencial, com tons anedóticos ${ }^{8}$.

O uso de material histórico na obra de Modesto Brocos y Gomez já era patente no seu trabalho visual, antes da publicação de Viaje a Marte. O autor se utilizou, em A Redenção de Cã (1895), da ideia de embranquecimento defendida por alguns setores da sociedade brasileira na transição entre o Império e a República. $O$ fato de ter sido premiado pela obra, demonstra que seu quadro apresentava uma adequação temática da natureza das previsões oficiais, interessantes ao jogo político e econômico brasileiros no contexto do fim da escravidão e início do incentivo ao processo imigratório que atenderia às demandas brasileiras

\footnotetext{
8 A anedota é aqui compreendida como um modo satírico que se utiliza de narrativas.
} 
por mão de obra. "Em três gerações o Brasil seria branco". Essa era a utopia histórica e oficial que o autor, em agenciamento identitário transcultural, transportou para sua obra, pensamento que pretendia explorar traços de uma brasilidade "mestiça" em construção.

A ideia da unificação das raças está presente em Viaje a Marte, e nela algumas especificidades se constituem no jogo da inverossimilhança acentuado desde as utopias renascentistas. O autor quer que suas ideias sejam praticadas, mas, ao mesmo tempo, dedica um significativo espaço para conjecturar acerca de instituições, como as religiosas, que, em seu texto tomam força como ideias absurdas para enfatizar os estranhamentos próprios em textos com modo anedótico. A exemplo, examinemos sua defesa de uma ordem religiosa, a das Humanitárias.

$\mathrm{O}$ tema se encontra presente em vários momentos da obra utópica de Brocos y Gomez, todavia, há um capítulo, em específico, em que o autor detalha o funcionamento da instituição, "uma das mais robustas da sociedade marciana" (Brocos y Gomez, 1930, p. 223). A Hermandad de Las Hermanas Humanitárias seria uma estratégia de grande destaque na cultura marciana. Por meio dela, muitos aspectos da sociedade poderiam ser corrigidos: da ordenação dos impulsos de conservação da espécie às práticas assistencialistas que envolviam trabalhos em asilos, internatos e hospitais. O ilustrado Feijoó lamenta não ter tratado do assunto em sua obra literária enquanto esteve na Terra. As Hermanas Humanitárias são apresentadas formalmente como irmãs de caridade, mas, na prática, agem como prostitutas sagradas. Suas funções sexuais são claras, como atender às "necessidades masculinas" zelando pela saúde, moralidade, práticas de higiene e prevenção de doenças. As Hermanas, inclusive, eram recrutadas em grupos para atender ao exército.

No capítulo em que Feijoó explica sobre as Hermanas, fica claro que a instituição se originou pelo fechamento de conventos nos "tempos bárbaros na Terra". Os conventos foram retiros de pessoas "ociosas", que viviam uma "vida egoísta e folgazã" (Idem, p. 224). Com as reformas, houve substituição dos conventos pelas casas das Hermanas, advindas das casas de prostituição, que "na Terra nunca foram devidamente valorizadas" (Idem, p. 229-230). Para o autor, as reformas em Marte deram outro status às prostitutas (embora o autor não use explicitamente esse nome), conferindo a elas uma posição de respeito e consideração das autoridades. As Hermanas possuíam espaços reservados nos teatros e nas igrejas e fora de seu ministério eram tratadas como virgens.

Embora enfatize a valorização social das Hermanas, o autor acaba por deixar à mostra os paradoxos da função quando explica 
como são recrutadas, ou mesmo, ao detalhar algumas das tarefas a que estavam submetidas essas mulheres. As Hermanas limpavam o convento e, dentre elas, havia jovens enviadas para lá como castigo por algum juiz. O recrutamento de tais mulheres ocorria por indicação das comunidades locais de higiene e elas eram escolhidas entre "as que não estavam aptas ao matrimônio, principalmente as histéricas, as de temperamento ardente e as voluntárias" (Idem, p. 226). Logo em seguida, o autor escreve que elas eram de todas as camadas sociais e que entrariam na irmandade a fim de serem "esposas da humanidade", em uma "orgulhosa, saudável e benéfica missão" (Idem, p. 226). Os homens que visitavam as Hermanas contribuíam com uma "limosna", que servia para as despesas do convento. As Hermanas faziam voto de pobreza, portanto não poderiam receber presentes ou pecúnias que as levassem a algum tipo de enriquecimento.

O caso das Hermanas criado por Modesto Brocos y Gomez nos remete aos apontamentos sobre o casamento feitos por More e Campanella mencionados anteriormente. A preocupação com a sexualidade, com o objetivo de garantir o equilíbrio social, é, portanto, uma preocupação dos utopistas desde as origens do gênero literário. Além disso, a crítica à sociedade de seu tempo e a ideia de que a ficção utópica possa se converter em realidade estão continuamente presentes na história das utopias.

A obra Viaje a Marte-bem como o quadro Redenção de Cã-mostram a visão do pintor-escritor espanhol sobre a questão racial no Brasil. O que hoje vemos como racismo é a forma como ele manejou as ideias utópicas de equilíbrio, pensando que o projeto de embranquecimento ao qual se associou eliminaria a desigualdade entre as raças. É claro que a sátira e o modo anedótico estão presentes, de forma que se cria certa ambiguidade, também uma característica das utopias.

A percepção de que as performances de Brocos y Gomez estejam enquadradas no pensamento utópico podem causar certa estranheza num primeiro momento, afinal as utopias estão associadas normalmente à justiça ou à perfeição - e as teorias que pregavam o embranquecimento da população são vistas hoje como racistas e coloniais, superadas. No entanto, examinando mais de perto as utopias, percebemos sua ancoragem histórica e superamos esse estranhamento anacrônico. $\mathrm{O}$ sonho do espanhol não é aplicável hoje, é certo, mas sua obra nos ajuda

9 Dinheiro que, tradicionalmente, definido nos Evangelhos e no Cristianismo Primitivo, se oferece, em troca de nada, aos pobres e necessitados, à conservação de templos ou para o clero. 
a compreender as relações entre o pensamento utópico, o socialismo e as teorias sociais pensadas no Brasil no fim do século XIX e começo do XX. É nisso, e não na efetivação da sua utopia, que está a sua importância.

\section{Referências}

BROCOS Y GOMEZ, Modesto. Viaje a Marte. Valencia: Arte y Letras, 1930.

CAMPANELlA, Thommaso. Cidade do Sol. Edição digital de Marcelo C. Barbão, 2002. Disponível em: <http://www.dominiopublico.gov.br>. Acesso em: 13 jul. 2012.

COLOMBO, Arrigo. Formas da utopia: as muitas formas e a tensão única em direção à sociedade de justiça. Morus - Utopia e Renascimento. Campinas, SP: UNICAMP-IEL/ Setor de Publicações, n. 3, p. 55-67, 2006.

DUBOIS, Claude-Gilbert. Problemas da utopia. Tradução de Ana Cláudia Romano Ribeiro. Campinas, SP: UNICAMP-IEL/Setor de Publicações, 2009.

GADAMER, Hans-Georg. Verdade e método. Petrópolis: Vozes, 1997.

HELLER, Agnes. O homem do Renascimento. Lisboa: Presença, 1982.

JAUREGUÍZAR, Augustín (Augusto Uribe). Españoles que fueron a Marte. Disponível em: <http://www.auguribe.com/esp_marte_01.htm>. Acesso em: 13 jul. 2012.

El Viaje a Marte de Modesto Brocos. Arbor: Ciência, Pensamento y Cultura. Madrid: Consejo Superior de Investigaciones Científicas, v. 185, n. 740, p. 13131322, 2009. Disponível em: <http://arbor.revistas.csic.es/index.php/arbor/article/view Article/397>. Acesso em: 13 jul. 2012.

MORE, Thomas. Utopia. Brasília: Editora da UnB, 2004.

PAIVA, Eduardo França. História \& Imagens. 2. ed. Belo Horizonte: Autêntica, 2004.

QUARTA, Cosimo. Utopia: gênese de uma palavra chave. Morus - Utopia e Renascimento. Campinas, SP: UNICAMP-IEL/Setor de publicações, n. 3, p. 35-53, 2006.

RIBEIRO, Ana Cláudia Romano. A Utopia e a Sátira. Morus - Utopia e Renascimento. Campinas, SP: UNICAMP-IEL/Setor de Publicações, n. 6, p. 139-147, 2009.

SARGENT, Lyman Tower. What is a Utopia? Morus - Utopia e Renascimento. Campinas, SP: UNICAMP-IEL/Setor de Publicações, n. 2, p. 153-157, 2005.

SCHWARCZ, Lilia Moritz. O espetáculo das raças: cientistas, instituições e questão racial no Brasil - 1870-1930. São Paulo: Companhia das Letras, 1993.

TROUSSON, Raymond. Historia de la literatura utópica: viajes a países inexistentes. Tradução Carlos Manzano. Barcelona: Ediciones Península, 1995.

. Utopia e utopismo. Morus - Utopia e Renascimento, Campinas, SP: UNICAMPIEL/Setor de Publicações, n. 2, p. 123-135, 2005.

WITEZE JR., Geraldo; BERRIEL, Carlos Eduardo Ornelas (orient.). O mundo é um grão de mostarda: a utopia do governo de Sancho Pança. 2010. 203 p. Dissertação (Mestrado) - Instituto de Estudos da Linguagem, Universidade Estadual de Campinas, Campinas, SP. Disponível em: $<$ http://www.bibliotecadigital.unicamp.br/ document/?code=000769136> . Acesso em: 28 ago. 2012. 